\title{
CEO Decision Making under Crisis: An Agency Theory Perspective
}

\author{
Amitrajit Sarkar \\ Ara Institute of Canterbury \\ New Zealand \\ sarkara@cpit.ac.nz \\ Stephen C. Wingreen \\ University of Canterbury \\ New Zealand \\ stephen.wingreen@canterbury.ac.nz \\ Paul Cragg \\ University of Canterbury \\ New Zealand \\ paul.cragg@canterbury.ac.nz
}

\begin{abstract}
Organisational resilience has gained increasing attention in recent years. This paper focuses on information systems resilience, which is an aspect of organisational resilience. Given the potentially devastating implications of disruptions to organisations, understanding the dynamics of the successful adaption of IS within organisations indicates an important avenue for future research. In this paper, we adopt Agency Theory to develop a conceptual framework, focused on decision making and planning for IS resilience. Concourse theory and Q-methodology were used to develop a Q-sort questionnaire, which was refined through interviews with researchers and IS professionals. The resulting 37 statements were then sorted by eight CEOs of Small Medium Enterprises (SME). Q-sort methodology identified three types of decision makers from the data, each representing distinct collective perspectives. These types are described and discussed, along with implications of findings as well as suggestions for future research.
\end{abstract}

Keywords: Information system resilience, Agency Theory, Small Medium Enterprises, Q-sort methodology, CEO decision making, disaster preparedness

Citation: Sarkar, A., Wingreen, S. C. and Cragg, P. (2017). " CEO Decision Making under Crisis: An Agency Theory Perspective," Pacific Asia Journal of the Association for Information Systems, 9(2), pp. 1-22. 


\section{Introduction}

Natural disasters, pandemic disease, and terrorist attacks all pose a severe threat to the continuity of an organisation's operation. Disasters can cause challenges to organisations and it is essential that sufficient effort is directed into making them robust and resilient to withstand these uncertainties and challenges. To a large extent, most organisations are dependent on information systems in their activities. Should there be a major disruption to the information systems services, it is practically impossible for the businesses to function with snail mails and paper based accounting. Therefore, when examining the crisis resilience of organisations, one crucial aspect is to examine the continuance of stable and reliable IS services (Gibb and Buchanan, 2006).

Although resilience is widely recognised in related disciplines such as, Computer Science, Crisis Management or Safety Engineering, there is very little attention paid by Information Systems scholars to IS resilience. Today, only a very small body of IS resilience research exists (Muller, Koslowski and Accorsi, 2013). An IBM study reported how organizations are increasingly adopting integrated business resilience strategies in an uncertain environment and large organisations lead the way in business and Information System resilience (IBM, 2011). Most studies on organisational resilience have been made in the context of big business, with few attempts to study smaller businesses, and to our current knowledge none of that research was on the topic of IS resilience. However, given the unique challenges faced by SMEs as organizations, research results obtained from the study of large enterprise IS cannot necessarily be generalized and transferred to SMEs (Thong, 1999). While the broader aim for this study is to examine organisational IS resilience in SMEs, this paper focuses on the first step of developing an instrument to understand the decision priorities of owner-managers of SMEs in the context of IS resilience. Small and Medium Sized Enterprises (SMEs) make a significant contribution to employment generation and economic growth of a nation (OECD, 2010; Ministry of Economic Development, 2012). SMEs in New Zealand represent 99 percent of the business population (NZ Ministry of Economic Development, 2012), and $99.7 \%$ of employer firms in the USA (SBA Office of Advocacy, 2012). The SME sector is often referred to as the backbone of the economy of a nation. Traditionally, SMEs have several advantages over larger companies due to their flexibility in adapting to change. However, by comparison to large firms, SMEs are more vulnerable and susceptible to various types of disaster, thus making IS resilience a more critical priority for SMEs, and consequently making SMEs an ideal population for beginning an investigation of IS resilience decision priorities and planning.

In this paper, the emphasis is on a relatively overlooked area of research: the entrepreneurs and owner-managers who own and operate these firms and their efforts to make their businesses resilient with regard to information systems. Much research to date has focused on characteristics of the firm (e.g. size, sector, performance and practices, etc.), and characteristics of the entrepreneur and owner-manager in an attempt to understand firm survival, growth and failure (Massey, 2005). However, little attention has been given to the characteristics of the entrepreneur and owner-manager and how they make decisions in time of crisis to ensure resilience. This research gap is surprising, as resilience is often said to be a combination of organisational and technical qualities and, therefore, a research topic well suited for IS research (Muller, Koslowski and Accorsi, 2013). Furthermore, SMEs are highly dependent on the entrepreneur or owner-manager as a leader, decision maker, manager and day-to-day operator of the firm (Storey and Greene, 2010), and therefore a study of SMEs 
should properly begin with their entrepreneurs and owner-managers.

Agency Theory has demonstrated significant predictive power with respect to the decision-making of business owners and managers by its proposition of the principal-agent relationship dynamics (Jensen and Meckling, 1976; Eisenhardt, 1989; Gurbaxani and Whang, 1991; Lee and Wingreen, 2010). Specifically, Agency Theory proposes that the misalignment of interests between the principals (owners) of a firm and the agents (managers) is a source of costs and losses to the firm (Jensen and Meckling, 1976; Eisenhardt, 1989). In the context of SMEs, where the owner and manager is frequently either the same person, or a small, tight-knit group of people, in theory there should be either very little or no misalignment of interests, and therefore very low costs associated with "agency problems", as they are called. For this reason, Agency Theory is adopted, since SMEs represent a theoretical ideal where principal-agent conflict is minimized.

The paper first reviews the literature on organisational resilience, SMEs, and Agency Theory. The paper then describes the research methodology, in which the methods and procedures prescribed by Concourse Theory are used to develop and test a set of Q-sort items. Further, we present the findings of our study. The paper concludes with the relevance of this research for both practitioners and academics and we propose some recommendations for further research in the area of IS resilience.

\section{Literature Review}

\section{Definition of IS Resilience}

The concept of resilience has been a prominent and emerging topic in various scientific fields, however, as resilience research encompasses a wide range of disciplines such as ecology, psychology or engineering, and different research contexts and topics, it is not surprising that the concept lacks an accepted common definition across disciplines (Muller, Koslowski and Accorsi, 2013). Rooted from the word resilire, meaning to spring back or to rebound, the term refers to "the ability to recover form and position elastically" (Muller, Koslowski and Accorsi, 2013). Against this background, resilience is defined as the ability of an organisation to not only survive but to thrive, both in good times and in the face of adversity (Seville, 2009). Vargo and Stephenson (2010) proposed that for organisations to invest in resilience, the business case for resilience investments has to go beyond insurance, and must be as good as the business cases for new equipment or new staff (Vargo and Stephenson, 2010).

After an extensive literature review we have not been able to find a definition of IS resilience. However, organisational resilience has been studied extensively by researchers (Vargo and Seville, 2011; Hatton, Seville, and Vargo, 2012). In order to define IS resilience we have utilised six attributes as identified by McManus (2008), namely overall situation awareness, decreased vulnerabilities and increased adaptability, risk intelligence, flexibility and agility. These terms are defined in Table 1.

A definition of Information Systems resilience is introduced based on these characteristics for the purpose of our study, it is defined as:

Information Systems resilience is a function of an organization's overall situation awareness related to Information Systems, management of Information Systems vulnerabilities, and adaptive capacity, risk intelligence, flexibility and agility of Information Systems in a complex, dynamic, and interconnected environment. 


\section{Table 1 - Attributes of IS Resilience}

\begin{tabular}{|l|l|}
\hline Set of Attributes & Definition \\
\hline Situation awareness & $\begin{array}{l}\text { It is the ability to identify and understand changes in the } \\
\text { environment. }\end{array}$ \\
\hline Management of Vulnerabilities & It is the capability to deal with the major vulnerabilities. \\
\hline Adaptive Capacity & $\begin{array}{l}\text { It is the capability to respond to and adapt to the changing } \\
\text { environment. }\end{array}$ \\
\hline Risk Intelligence & It is the ability to identify and anticipate risks. \\
\hline Flexibility & It is the ability to change. \\
\hline Agility & $\begin{array}{l}\text { It is the ability to produce timely responses to changing environment } \\
\text { and conditions. }\end{array}$ \\
\hline
\end{tabular}

\section{Resilience of Organisations}

Gibson and Tarrant (2010) presented the integrated functions model which suggests that organisational resilience is a goal that results from a combination of activities such as risk management and business continuity.

Gibson and Tarrant (2010) also presented the herringbone resilience model shown as Figure 1. This model suggests that resilience is enhanced by a combination of an organisation's characteristics or attributes and their activities and capabilities (Gibson and Tarrant, 2010). The herringbone model is important in the context of this research, since it incorporates many of the factors considered as possible indicators of IS resilience.

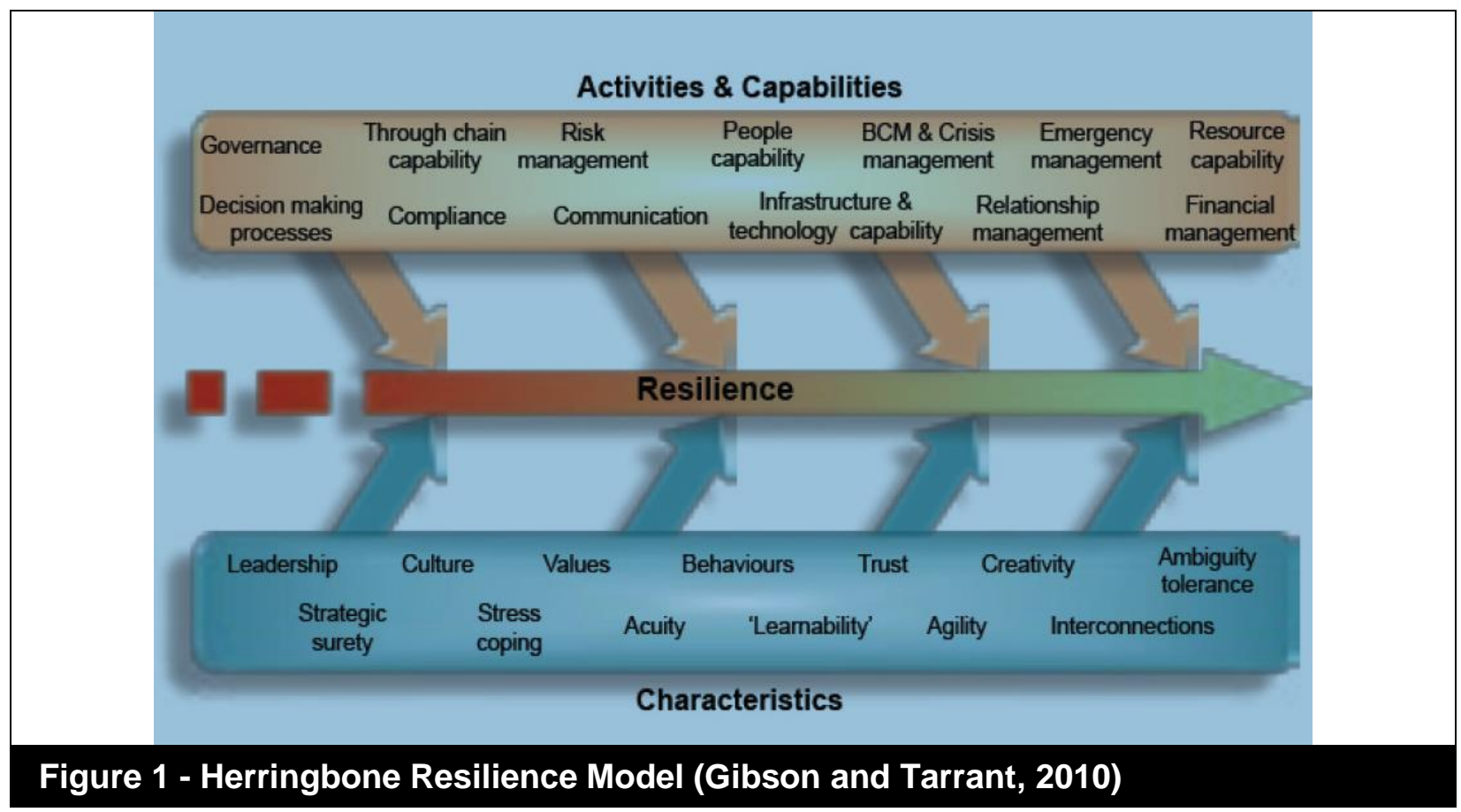


The 'herringbone' recognises that an organisation possesses a substantial range of capabilities and undertakes a range of activities that will contribute towards improved resilience. Furthermore, the organisation also exhibits a number of characteristics that will affect its capabilities and activities to enhance the organisation's resilience (Gibson and Tarrant, 2010).

For most firms today, much business is done with vendors and customers on the Internet; they rely heavily on IT and data, and operate 24/7. For this reason, the line between business and information systems is blurred (Sayana, 2005). In such cases, continued availability of information systems is a sine qua non for business. Such businesses do not have any other alternate means of recording transactions and other data, hence cannot afford to be without information systems for long. All businesses that use information systems and data in their operations have a need for business continuity and a disaster recovery plan. Most large organisations, particularly all Fortune 1000 enterprises, conduct regular IS audits to ensure confidentiality, integrity and continuous availability of information systems (Singleton, 2011). Hence, continued availability of information systems is one of the major criteria for IS resilience.

However, a small enterprise that uses IT and whose business processes are reliant on IT is also at high risk (Singleton, 2011). Goodwin (2005) noted that SMEs are particularly weak in demonstrating their plans for the business continuity of their IT systems. Goodwin (2005) predicted that SMEs will soon be under pressure from large businesses, regulators, investors, insurers and their suppliers to demonstrate resilience. Thus, it will be hard for them to ignore business continuity in the future. Although structured planning processes can be good for SMEs (Cragg and King, 1993), SMEs are much less likely to carry out such planning processes than larger organisations and, when they do, the planning is likely to be less disciplined (Berman et al., 1997).

\section{Planning and Resilience}

Discussion on resilience is incomplete unless we explore planning. A central theme of resilience research is the question of anticipation vs. resilience, and planning vs. adaptation. Anticipation involves predicting possible sources of failure or causes of crisis or disaster, so that they can be planned for, mitigated, or avoided altogether. Weick and Sutcliffe (2007) refer to this as avoiding error by design, whereby a system of controls, processes and checks is put in place to prevent possible crises from occurring. Weick and Sutcliffe (2007) added that an anticipatory approach is more suited to environments characterised by stability and predictable outcomes.

In contrast, resilience involves being flexible in a changing environment. Weick and Sutcliffe (2007) discuss the resilience approach and note that resilient organisations recognise that it is impossible to prevent all crises and disasters all of the time. Instead they monitor their organisation as a system with inputs and outputs, the characteristics of which can provide information about the health of the whole system. Both planning and resilience involve the evaluation and prioritization of a multitude of factors, the prioritization of those factors with reference to one another, and decisions that ultimately reflect the priorities of the decision maker. Therefore it is necessary to adopt a strategy and methods that support prioritization of a multitude of decision criteria.

Optimally, businesses should find the most efficient balance, or "equilibrium" between anticipation and resilience. Comfort (2001) argues that disaster management practices are moving towards a combination of anticipation and resilience strategies. "While we agree that resilience is the key to coping, it is necessary to organise for resilience" (Comfort, 2001). Research also suggests that the anticipatory approach, including planning, is used to enable organisations to be resilient. Planning and formalising response arrangements in advance 
means that the organisation is free, at the time of crisis, to be much more adaptive and resilient in its response (Teoh and Zadeh, 2013). Thus, instead of planning for an uninterrupted and continuous operation, a resilient organisation is able to recognise disturbances and circumvent risk with an ability to adapt and reconfigure as quickly as appropriate, either to bring the organisation to the optimal operational position, or to converge to a new optimal operating position (Teoh and Zadeh, 2013).

\section{Definition of SMEs}

Research has highlighted that there is no precise definition of SMEs (Bhamra et al., 2011). As SMEs differ in size, location, business, financial performance, maturity and management style, the definition of SMEs varies from country to country.

In New Zealand, for instance, government statistics define SMEs as those businesses having fewer than 20 full time equivalent employees (NZ Ministry of Economic Development, 2012), whereas in the USA an SME is a business with less than 500 employees (SBA Office of Advocacy, 2012). "Small" is culturally relative, but the generalised characteristics of these firms are that they have limited access to resources, personalised management styles and little formal structure (Battisti et al., 2009). Our research is conducted in New Zealand, and therefore we will define SMEs as businesses that are "privately owned, have personalised management styles, little formal structures and employ less than 20 full time staff members."

It is well known that SMEs are different from large organisations in many respects, and organizational theories applicable to large firms may not be applicable to SMEs (Thong, 1999). It is important to remember that a small firm is "not a little big business," (Thong, 1999). Thus, care should be taken when studying technology issues in small firms (Thong, 1999). We will elaborate and explain some of these differences from the perspective of Agency Theory.

\section{Agency Theory Effects in SMEs}

Agency Theory applies to situations where one or more persons (the principals) engage another person or persons (the agents) to perform some service on their behalf, which includes delegating some decision making authority to the agent. "If both parties to the relationship are utility maximisers then there is good reason to believe the agent will not always act in the best interests of the principal" (Jensen and Meckling, 1976). Agency Theory predicts that the agency conflict may be reduced when the owner is involved in management (Fama and Jensen, 1983; Jensen and Meckling, 1976). Principal-agent conflict may be less pronounced in the case of smaller organisations where it is more likely that the principal and agent will have a close relationship. On the other hand, it is also true that managers in small firms may be more isolated from the market discipline due to a closer relationship with their principals. Such isolation may result in entrenchment. Entrenchment is, in turn, likely to have a negative impact on performance. Furthermore, isolation from market disciplines and entrenchment-induced inertia is likely to encourage a weak culture and weak leadership as well as a myopic strategy (Ghobadian and O'Regan, 2006).

However, in SMEs, the CEO is usually also the owner-manager. Since the CEO is the main decision maker, the managerial style and personal traits of the CEO could potentially influence the culture, leadership and strategic planning processes of an SME (Ghobadian and O'Regan, 2006). Therefore, in the case of an SME with a single CEO owner-manager, decision priorities reflect the risk tolerance or risk aversion of the owner-manager, and often do not include "agency effects" related to the misaligned interests of other decision makers. In other words, by definition there can be no principal-agent conflict when the principal acts on his own behalf as the manager of the business, and therefore SMEs with a single CEO owner-manager 
represent a theoretical ideal in the context of Agency Theory.

The owner-manager's desire for autonomy and possible disposition towards social aspects of relationships should not be ignored when trying to better understand the dynamics of power within SMEs. Implementing change can be particularly problematic for organisations where power and authority are highly centralised (Paton, 2007). Competitor power is also of concern to SMEs, especially when buyers can at short notice switch suppliers (Saunders, 1997).

In summary, based on the arguments and predictions of Agency Theory, SMEs and large organisations are likely to behave differently. Moreover, Agency Theory predicts differences in leadership style, culture, the emphasis placed on different dimensions of the strategy making process, barriers to the implementation of strategy and performance between SMEs and large organisations. The transformational leadership style is more prevalent in SMEs, while the transactional leadership style is more prevalent in large organisations. SMEs and large organisations also differ across a number of culture constructs. Large organisations are more likely to have formal strategic plans than SMEs. The personal traits of CEOs could potentially influence the culture, leadership, and strategic planning processes of an SME.

Overall, it is evident from our literature review that the form of IS resilience in large organisations may not be directly applicable to SMEs. Whereas in large firms, a study of the firm involves the study of its network of principals and agents, their interrelationships, and decision structures intended to make them function as if they were of one mind and purpose; in SMEs we often find that the firm and the CEO ownermanager are one and the same. In other words, to study the decision priorities of SMEs is to study their CEOs, and to study CEOs of SMEs is to study their firms' decision priorities. In the context of this research, SMEs represent a theoretical ideal of a business that has minimal or no principal-agent conflict, but a greater exposure to threats from poor IS resilience on account of CEO entrenchment or isolation from market discipline. Therefore, a study of SME CEOs in a post-disaster context should predictably result in a very rich and deep understanding of the dynamics of IS resilience planning priorities.

\section{Research Model}

A conceptual framework of determinants of IS resilience, and therefore what ought to be the decision priorities for one who is responsible for IS resilience, is presented in Figure 2.

Internal and external factors presented in the above framework of IS resilience for SMEs were derived from the literatures discussed in the previous section. In the context of this research, the model provides a guide for the development of instrumentation, and interpretation of the results. 


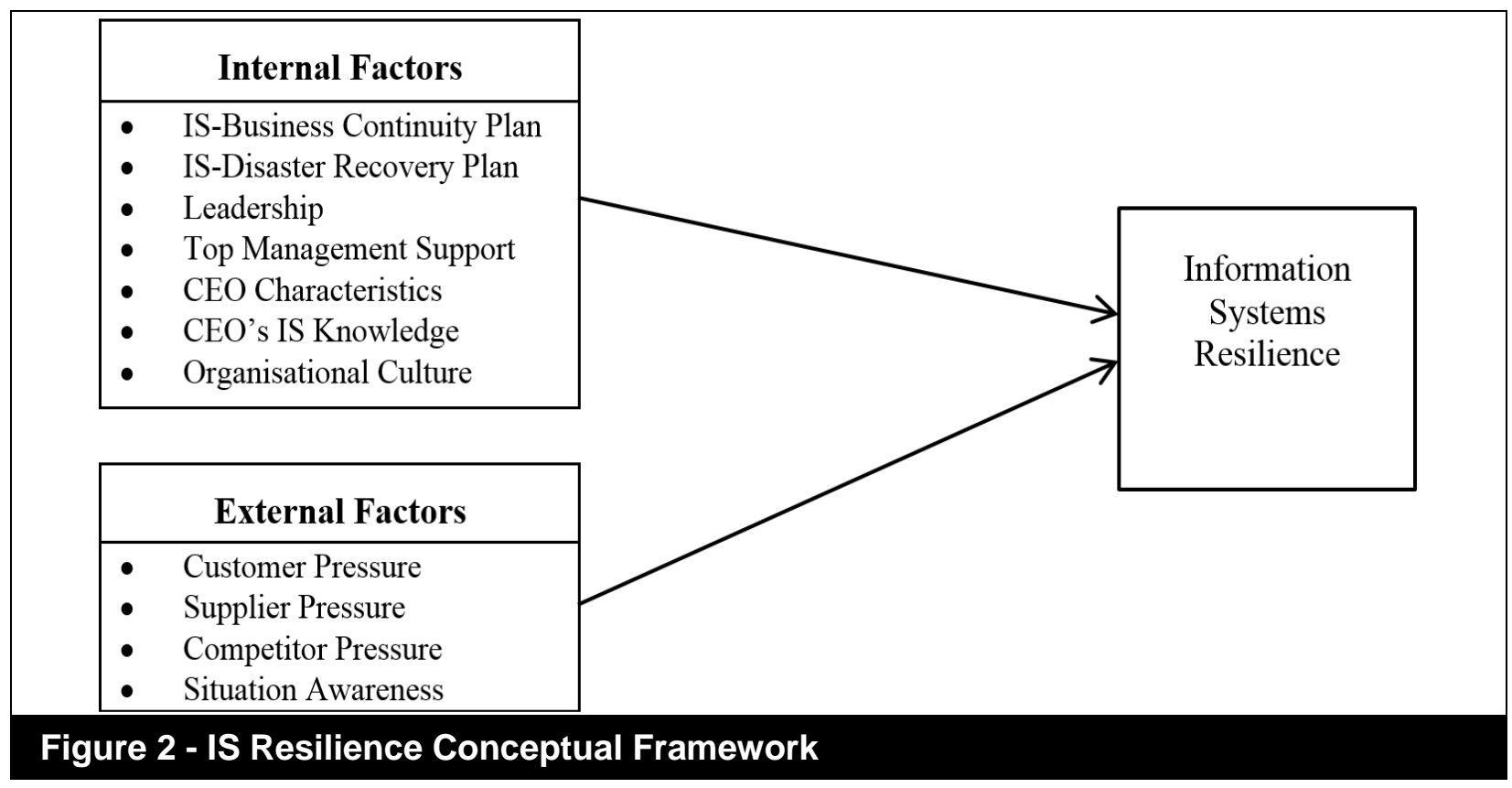

\section{Research Method}

Concourse Theory is a theory of communicability which proposes that people live their lives within a universe of possible thoughts, ideas, feelings, and related referential material (Brown, 1980; Stephenson, 1986a \& 1986b; Wingreen and Blanton, 2017). The universe of possibilities for any given topic is a "concourse", and each person possesses a unique perspective of the concourse that is reflected by their own personal prioritization of the content of the concourse. Concourse Theory prescribes Q-methodology as the principal means of operationalizing a concourse, and the perspectives of people with reference to the concourse. To operationalize the person's unique perspective of a concourse, Q-methodology proposes the Q-sort and Q-factor analysis (Stephenson, 1986 - 1988; Wingreen, Lerouge and Blanton, 2009; Klaus, Wingreen, and Blanton, 2010; Wingreen and Blanton, 2017). A Q-sort requires the person to sort through a field of statements that represent the concourse, and to classify those statements into a quasi-normal distribution, typically between "most important" and "most unimportant", or "most desirable" and "most undesirable". In doing so, the Q-sort captures the person's priorities with respect to the concourse, and operationalizes their unique perspective. Therefore, Concourse Theory, Qmethodology, and the Q-sort are also appropriate to operationalize the decision priorities of CEO owner-managers in SMEs, since in their planning and decision making, they also work within a "concourse" of criteria related to IS resilience.

\section{Instrument Development}

The Q-sort instrumentation, a set of $37 \mathrm{Q}$ sort statements, was developed according to the guidelines delineated by previous research (Brown, 1980; Stephenson, 1986a, and 1986b). The concourse is the unit of analysis, and therefore a set of Q-sort statements should represent the concourse of interest in the same way that a sample of people should represent the population in a classical correlational study. Therefore, certain prescribed guidelines are adopted in the selection of statements so as to achieve the highest probability of "representativeness" of the domain of the concourse: 1) review of the literature, 2) conversations and interviews with people who participate in the concourse, and 3) 
input from domain experts about the content of the sample of Q-statements (Brown, 1980; Dennis, 1988).

Furthermore, if there are areas of theoretical interest, as there are in this research, then a "structured q-set" may be developed, which balances the number of $\mathrm{Q}$-statements in each theoretical category, in much the same way as experimental participants are assigned to groups for balanced experimental designs in classical experimental research (Watts and Stenner, 2012). To accomplish this, we selected statements from figures 1 and 2 to represent the various dimensions of IS resilience which should be reflected in the decision priorities of SME CEOs. These items were then coded according to whether they might be desirable for small firms according to Agency Theory, and risk tolerant or risk-averse decision makers. Therefore, the final set of 37 items was both representative of the larger concourse and well-balanced with regard to all the theoretical categories of interest in the current research.

\section{The Q-Sample}

The complete set of Q-sort statements is also known as the "Q-sample", since it represents a sample of the universe of the concourse. The Q-sample consists of thirtyseven statements related to CEO decision priority on IS resilience in SME context, as noted below.

\section{Table 2 - IS Resilience Factors, Agency Theory Explanation Mapped to Q-Statements}

\begin{tabular}{|c|c|c|}
\hline IS Resilience Factors & $\begin{array}{ll}\text { Agency } & \text { Theory } \\
\text { Explanation } & \end{array}$ & Q-Statements \\
\hline $\begin{array}{l}\text { Business Impact Analysis / } \\
\text { Organisational Culture }\end{array}$ & Large Organisations & $\begin{array}{l}\text { Organisational vulnerability and capacity } \\
\text { assessments carried out which provide } \\
\text { comprehensive picture of vulnerabilities and } \\
\text { capacities. }\end{array}$ \\
\hline CEO Characteristics & $\begin{array}{l}\text { Risk Averse \& Large } \\
\text { Organisations }\end{array}$ & Ability to identify key risks \\
\hline CEO Characteristics & $\begin{array}{l}\text { Risk Averse \& Large } \\
\text { Organisations }\end{array}$ & Ability to anticipate surprises and crises \\
\hline $\begin{array}{l}\text { CEO's IS Knowledge / } \\
\text { Aligning IT with Business } \\
\text { Strategy }\end{array}$ & Large organisations & Adapting technology to strategic change \\
\hline Commitment / Leadership & Large Organisations & $\begin{array}{l}\text { Committed, effective and accountable } \\
\text { leadership of IS resilience planning and } \\
\text { implementation. }\end{array}$ \\
\hline $\begin{array}{l}\text { Commitment / Top } \\
\text { Management Support }\end{array}$ & $\begin{array}{l}\text { Large and Small } \\
\text { Organisations }\end{array}$ & $\begin{array}{l}\text { Top management support and commitment to } \\
\text { IS resilience. }\end{array}$ \\
\hline $\begin{array}{l}\text { Commitment/ Risk } \\
\text { Management / Monitoring }\end{array}$ & Large Organisations & $\begin{array}{l}\text { On-going monitoring of hazards and risks and } \\
\text { updating of plans. }\end{array}$ \\
\hline Communication & $\begin{array}{l}\text { Large and Small } \\
\text { Organisations }\end{array}$ & $\begin{array}{l}\text { Use IS network to communicate with the } \\
\text { customers. }\end{array}$ \\
\hline Communication & Large Organisations & $\begin{array}{l}\text { The extent of follow-up with customers for } \\
\text { feedbacks. }\end{array}$ \\
\hline $\begin{array}{l}\text { Communication / } \\
\text { Relationship Management }\end{array}$ & Large Organisations & $\begin{array}{l}\text { Organisation's IS resilience plan shared with } \\
\text { all suppliers. }\end{array}$ \\
\hline Competitor Pressure & Small Organisations & $\begin{array}{l}\text { Our competitors are developing and } \\
\text { enhancing their IS resilience capabilities. }\end{array}$ \\
\hline Connection & $\begin{array}{l}\text { Large and Small } \\
\text { Organisations }\end{array}$ & $\begin{array}{l}\text { Use IS networks to connect to supplier's } \\
\text { databases. }\end{array}$ \\
\hline Decision making process & Large Organisations & Select suppliers with robust resilience plan. \\
\hline Financial Management & Small Organisations & $\begin{array}{l}\text { A sound IS resilience plan will help us to win } \\
\text { more business contracts. }\end{array}$ \\
\hline Financial Management & Small Organisations & $\begin{array}{l}\text { A sound IS resilience plan will help us to pay } \\
\text { lesser insurance premium. }\end{array}$ \\
\hline
\end{tabular}


Pacific Asia Journal of the Association for Information Systems, Vol. 9, Iss. 2 [2017], Art. 2

CEO Decision Making under Crisis: An Agency Theory Perspective / Sarkar et al.

\begin{tabular}{|c|c|c|}
\hline $\begin{array}{l}\text { Infrastructure \& Technical } \\
\text { Capability }\end{array}$ & Large Organisations & $\begin{array}{l}\text { Resilient and accessible critical facilities (e.g. } \\
\text { back-up systems, redundancy of data). }\end{array}$ \\
\hline $\begin{array}{l}\text { Infrastructure \& Technical } \\
\text { Capability }\end{array}$ & Large Organisations & $\begin{array}{l}\text { Setting up information disaster recovery } \\
\text { system (e.g., disk redundancy, backup } \\
\text { facility). }\end{array}$ \\
\hline $\begin{array}{l}\text { Infrastructure \& Technical } \\
\text { Capability }\end{array}$ & Large organisations & Capability for disaster recovery \\
\hline $\begin{array}{l}\text { Infrastructure \& Technical } \\
\text { Capability }\end{array}$ & Large organisations & $\begin{array}{l}\text { Providing the organizational units with } \\
\text { information for } 24 \text { hours a day, } 7 \text { days a week }\end{array}$ \\
\hline $\begin{array}{l}\text { Infrastructure \& Technical } \\
\text { Capability / CEO's IS } \\
\text { Knowledge }\end{array}$ & $\begin{array}{l}\text { Large and Small } \\
\text { Organisations }\end{array}$ & $\begin{array}{l}\text { Use cloud computing to back up } \\
\text { organisational data. }\end{array}$ \\
\hline $\begin{array}{l}\text { Leadership / CEO's IS } \\
\text { Knowledge }\end{array}$ & Large Organisations & $\begin{array}{l}\text { IS resilience can provide an organisation with } \\
\text { an edge over its competitors. }\end{array}$ \\
\hline $\begin{array}{l}\text { Leadership / CEO's IS } \\
\text { Knowledge }\end{array}$ & Large Organisations & $\begin{array}{l}\text { Long-term IS Resilience, Business Continuity, } \\
\text { Disaster recovery justification and planning. }\end{array}$ \\
\hline Learnability & Large Organisations & Full scale Competitor analysis. \\
\hline Learnability & Large Organisations & Study resilience strategies of competitors. \\
\hline Organisational Culture & $\begin{array}{l}\text { Risk Averse \& Large } \\
\text { Organisation }\end{array}$ & $\begin{array}{l}\text { The level of customer involvement in } \\
\text { preparing resilience, business continuity and } \\
\text { disaster management plans. }\end{array}$ \\
\hline Organisational Culture & $\begin{array}{l}\text { Risk Averse \& Large } \\
\text { Organisation }\end{array}$ & $\begin{array}{l}\text { The level of supplier involvement in preparing } \\
\text { resilience, business continuity and disaster } \\
\text { management plans. }\end{array}$ \\
\hline Organisational Culture & Large organisations & $\begin{array}{l}\text { Aligning IS strategies with the strategic plan of } \\
\text { the organization }\end{array}$ \\
\hline BCM Planning & Large Organisations & $\begin{array}{l}\text { Organisation IS Continuity plans, developed } \\
\text { through participatory processes, put into } \\
\text { operation and updated periodically. }\end{array}$ \\
\hline DR Planning & Large Organisations & $\begin{array}{l}\text { IS Disaster Recovery plans informed by } \\
\text { understanding of underlying causes of } \\
\text { vulnerability and other factors outside } \\
\text { organisation's control. }\end{array}$ \\
\hline Planning & $\begin{array}{l}\text { Risk Averse \& Large } \\
\text { Organisations }\end{array}$ & $\begin{array}{l}\text { IS resilience plan that is well defined and } \\
\text { structured }\end{array}$ \\
\hline Planning & $\begin{array}{l}\text { Risk Tolerant \& Small } \\
\text { Organisations }\end{array}$ & IS resilience plan that is flexible and adaptable \\
\hline $\begin{array}{l}\text { Planning / Resource } \\
\text { Capability }\end{array}$ & Large Organisations & $\begin{array}{l}\text { A sound IS resilience plan will help our } \\
\text { organisation to make more efficient use of } \\
\text { resources. }\end{array}$ \\
\hline $\begin{array}{l}\text { Risk Management / Situation } \\
\text { Awareness }\end{array}$ & Large Organisations & $\begin{array}{l}\text { Organisation hazard/risk assessments carried } \\
\text { out which provide comprehensive picture of all } \\
\text { major hazards and risks faced by organisation } \\
\text { (and potential risks). }\end{array}$ \\
\hline Situation Awareness & Large organisations & $\begin{array}{l}\text { Understanding the strategic priorities of top } \\
\text { management }\end{array}$ \\
\hline $\begin{array}{l}\text { Trust / Organisational } \\
\text { Culture }\end{array}$ & $\begin{array}{l}\text { Large and Small } \\
\text { Organisations }\end{array}$ & Ensuring data security \\
\hline $\begin{array}{l}\text { Trust / Organisational } \\
\text { Culture / Customer Pressure }\end{array}$ & $\begin{array}{l}\text { Large and Small } \\
\text { Organisations }\end{array}$ & $\begin{array}{l}\text { Providing reliable and consistent services to } \\
\text { customers }\end{array}$ \\
\hline $\begin{array}{l}\text { Trust / Organisational } \\
\text { Culture / Supplier Pressure }\end{array}$ & $\begin{array}{l}\text { Large and Small } \\
\text { Organisations }\end{array}$ & $\begin{array}{l}\text { Providing reliable and consistent services to } \\
\text { Suppliers }\end{array}$ \\
\hline
\end{tabular}

\section{The P-Sample}

The people who participate in a Q-method study are referred to as the "P-set" or "Psample".
After the $2010-2011$ earthquakes in Christchurch, private sector CEO ownermanagers of local SMEs were recruited to assist as evaluators with the item selection phase. Following the guidelines for 
instrument development, feedback from the evaluators was incorporated into the $Q$ statement and Q-Sort instrumentation. After several iterations of the instrument development guidelines, the evaluators confirmed that the instrument is representative of the concourse and should function as intended.

We then approached eight (8) private sector CEO owner-managers of local SMEs, who provided their own Q-sorts. A short questionnaire was distributed to all participants to gather demographic and contextual information, such as industry sector they operate in, tenure in position and budget allocations to ensure P-sample variation. All eight (8) participants responded to the questionnaire and thus were included in the P-sample. Although the goals of $Q$-method research do not require a representative $\mathrm{P}$-sample, since the concourse is the unit of analysis rather than the person, the $\mathrm{P}$-sample is nonetheless sufficiently diverse with respect to each of the major demographic factors. In addition, the restriction of the sample to Christchurch local CEOs was intentional, in order to serve as a control for region variations, and to ensure that all participants were in fact involved in post-disaster planning.

The data gathered was analysed using the PQ-method software that is commonly used in Q-methodology research (Wingreen and Blanton, 2017).

\section{Organisation Exposure to Crisis}

The Christchurch Earthquake was in fact a sequence of earthquakes from September 2010 to mid-2011. The earthquake that caused the most damage occurred in February 2011, several months after the first earthquake in September 2010. Prior to the Sept. 2010 earthquake, none of the organisations had earthquake plans in place, because it was widely believed that earthquakes were extremely unlikely, or not possible in Christchurch. By the time this study was conducted, all companies in this study had earthquake plans in place.

The organisations in this study experienced a variety of challenges as a result of the Christchurch earthquake. Common to all of them was trouble with the communications network, electricity outages, and employee personal issues that followed in the days after the earthquake. All companies had subsequently developed and put in place a robust and rehearsed system for earthquake safety measures, with assigned duties, floor announcements and evacuation zones. Business Continuation Plans and Disaster Recovery plans had been prepared, special control rooms been set up, and a task list and contact tree for emergencies had been drawn up. Therefore, no company was taken entirely unawares by the February 2011 earthquake. All of the companies had their primary activities or core units within the earthquake-hit Christchurch area, and as a result all of them suffered a devastating blow to their operations. The scale of the disaster was shocking even for these well prepared New Zealand companies.

\section{Research Findings and Discussion}

This section presents the findings of this research that were reached through analysis of Q-sort data. The Q-sort data was analysed using a centroid factor analysis, as suggested by prior research. Two, three and four-factor solutions were examined at first, however, since the four-factor solution converged to a three-factor solution, there was no need to continue, and a three-factor solution was adopted. 


\begin{tabular}{|c|c|c|c|c|c|c|}
\hline \multirow[t]{2}{*}{ Statements } & \multicolumn{2}{|c|}{ Type 1} & \multicolumn{2}{|c|}{ Type 2} & \multicolumn{2}{|c|}{ Type 3} \\
\hline & $z$ & rank & $z$ & rank & $z$ & rank \\
\hline $\begin{array}{l}\text { 1. IS DR plans informed by understanding of underlying } \\
\text { causes of vulnerability and other factors outside } \\
\text { organisation's control. }\end{array}$ & 1.49 & 5 & 1.36 & 6 & 0 & 21 \\
\hline $\begin{array}{l}\text { 2. Organisation ISCP plans, developed through } \\
\text { participatory processes, put into operation and updated } \\
\text { periodically. }\end{array}$ & 0.49 & 11 & 0.68 & 12 & -0.54 & 29 \\
\hline $\begin{array}{l}\text { 3. Organisation's IS resilience plan shared with all } \\
\text { suppliers. }\end{array}$ & -0.75 & 30 & -2.04 & 37 & -1.12 & 35 \\
\hline $\begin{array}{l}\text { 4. Organisation hazard/risk assessments carried out } \\
\text { which provide comprehensive picture of all major hazards } \\
\text { and risks faced by organisation (and potential risks). }\end{array}$ & 0.3 & 17 & 0.68 & 12 & 0 & 21 \\
\hline $\begin{array}{l}\text { 5. On-going monitoring of hazards and risks and updating } \\
\text { of plans. }\end{array}$ & 0.24 & 18 & 1.36 & 6 & 0.78 & 9 \\
\hline $\begin{array}{l}\text { 6. Organisational vulnerability and capacity assessments } \\
\text { carried out which provide comprehensive picture of } \\
\text { vulnerabilities and capacities. }\end{array}$ & 0.3 & 17 & 0.68 & 12 & 0 & 21 \\
\hline $\begin{array}{l}\text { 7. Resilient and accessible critical facilities (e.g. back-up } \\
\text { systems, redundancy of data). }\end{array}$ & 1.55 & 3 & 2.04 & 2 & 1.22 & 5 \\
\hline $\begin{array}{l}\text { 8. Top management support and commitment to IS } \\
\text { resilience. }\end{array}$ & 0.22 & 20 & 0.68 & 12 & 1.22 & 5 \\
\hline $\begin{array}{l}\text { 9. IS resilience can provide an organisation with an edge } \\
\text { over its competitors }\end{array}$ & -1.24 & 33 & -1.36 & 36 & -0.34 & 26 \\
\hline $\begin{array}{l}\text { 10. Our competitors are developing and enhancing their } \\
\text { IS resilience capabilities }\end{array}$ & -2.29 & 36 & -1.36 & 36 & -2.34 & 37 \\
\hline $\begin{array}{l}\text { 11. A sound IS resilience plan will help us to win more } \\
\text { business contracts }\end{array}$ & -0.67 & 29 & -1.36 & 36 & 0.34 & 14 \\
\hline $\begin{array}{l}\text { 12. A sound IS resilience plan will help us to pay lesser } \\
\text { insurance premium }\end{array}$ & -0.8 & 31 & -2.04 & 37 & -1.9 & 37 \\
\hline $\begin{array}{l}\text { 13. A sound IS resilience plan will help our organisation to } \\
\text { make more efficient use of resources }\end{array}$ & $\begin{array}{l}-1.68 \\
\end{array}$ & 36 & -0.68 & 32 & 0.44 & 12 \\
\hline $\begin{array}{l}\text { 14. Long-term IS Resilience, Business Continuity, } \\
\text { Disaster recovery justification and planning }\end{array}$ & -0.53 & 27 & 0 & 26 & -0.34 & 26 \\
\hline 15. Competitor analysis & -1.49 & 34 & -1.36 & 36 & -1.32 & 36 \\
\hline $\begin{array}{l}\text { 16. Setting up information disaster recovery system (e.g., } \\
\text { disk redundancy, backup facility) }\end{array}$ & 0.54 & 8 & 2.04 & 2 & 0 & 21 \\
\hline 17. Study resilience strategies of competitors & -1.83 & 35 & -0.68 & 32 & -1.12 & 35 \\
\hline 18. Select suppliers with robust resilience plan & 0.45 & 13 & 0 & 26 & 1.56 & 3 \\
\hline 19. Use IS network to communicate with the customers. & 0.47 & 12 & 0 & 26 & -0.34 & 26 \\
\hline 20. Use IS networks to connect to supplier's databases & 0.39 & 14 & -0.68 & 32 & -0.88 & 32 \\
\hline 21. Use cloud computing to back up organisational data & -0.1 & 24 & 0.68 & 12 & 0.1 & 15 \\
\hline $\begin{array}{l}\text { 22. The level of customer involvement in preparing } \\
\text { resilience, business continuity and disaster management } \\
\text { plans }\end{array}$ & -1.17 & 32 & 0 & 26 & -0.68 & 30 \\
\hline 23. The extent of follow-up with customers for feedbacks & -1.22 & 33 & -0.68 & 32 & -1.12 & 35 \\
\hline $\begin{array}{l}\text { 24. The level of supplier involvement in preparing } \\
\text { resilience, business continuity and disaster management } \\
\text { plans }\end{array}$ & -0.14 & 25 & 0 & 26 & -0.78 & 31 \\
\hline 25. Ensuring data security. & -0.17 & 26 & 1.36 & 6 & 1.02 & 7 \\
\hline $\begin{array}{l}\text { 26. Providing reliable and consistent services to } \\
\text { Suppliers. }\end{array}$ & 0 & 22 & -0.68 & 32 & -0.2 & 22 \\
\hline $\begin{array}{l}\text { 27. Providing reliable and consistent services to } \\
\text { customers. }\end{array}$ & 1.97 & 1 & 0 & 26 & 1.12 & 6 \\
\hline 28. Capability for disaster recovery. & 0.76 & 6 & 0 & 26 & 0 & 21 \\
\hline
\end{tabular}




\begin{tabular}{|l|l|l|l|l|l|l|}
\hline $\begin{array}{l}\text { 29. Providing the organizational units with information for } \\
\text { 24 hours a day, 7 days a week. }\end{array}$ & $\mathbf{0 . 5}$ & $\mathbf{1 0}$ & -0.68 & $\mathbf{3 2}$ & $\mathbf{2 . 3 4}$ & $\mathbf{1}$ \\
\hline $\begin{array}{l}\text { 30. Understanding the strategic priorities of top } \\
\text { management. }\end{array}$ & 0.11 & $\mathbf{2 1}$ & $\mathbf{0}$ & $\mathbf{2 6}$ & 0.34 & $\mathbf{1 4}$ \\
\hline $\begin{array}{l}\text { 31. Aligning IS strategies with the strategic plan of the } \\
\text { organization. }\end{array}$ & 0.5 & $\mathbf{1 0}$ & 0 & $\mathbf{2 6}$ & 0 & $\mathbf{2 1}$ \\
\hline 32. Adapting technology to strategic change. & -0.61 & $\mathbf{2 8}$ & 0 & $\mathbf{2 6}$ & -0.34 & $\mathbf{2 6}$ \\
\hline 33. IS resilience plan that is well defined and structured. & 0.76 & $\mathbf{7}$ & 0 & $\mathbf{2 6}$ & -0.44 & $\mathbf{2 8}$ \\
\hline 34. IS resilience plan that is flexible and adaptable. & 0.3 & $\mathbf{1 5}$ & 0 & $\mathbf{2 6}$ & -0.44 & $\mathbf{2 8}$ \\
\hline 35. Ability to identify key risks. & 1.52 & $\mathbf{4}$ & 0.68 & $\mathbf{1 2}$ & 0.88 & $\mathbf{8}$ \\
\hline 36. Ability to anticipate surprises and crises. & 1.61 & $\mathbf{2}$ & 0 & $\mathbf{2 6}$ & 0.44 & $\mathbf{1 2}$ \\
\hline $\begin{array}{l}\text { 37. Committed, effective and accountable leadership of IS } \\
\text { resilience planning and implementation. }\end{array}$ & -0.03 & $\mathbf{2 3}$ & 0 & $\mathbf{2 6}$ & $\mathbf{2}$ & $\mathbf{2}$ \\
\hline
\end{tabular}

Table 3 reports the results of the factor analysis, which reveals three "types" of decision priorities held by the CEOs who participated. The $z$-scores are the average z-statistic for where the statement was ranked on the Q-sort distribution by those who comprise that factor, and as such represent the probabilities associated with each priority for their respective decision type. The "rank" is the average ranking of that statement by those who represent that factor. The highest and lowest rankings are highlighted so as to illustrate the decision priorities that represent each type. A type is defined by both the high and low priorities, since both distinguish any given type from others, and therefore the analysis proceeds by interpreting and defining the types based on their respective priorities. At this stage, the existence of a type means only that the type exists among those participating in the current study. A larger study will almost certainly reveal additional types. Further research with larger data sets will eventually reveal the relative proportions of these types among the population of decisionmakers and the probabilities associated with each type.

\section{Type 1: Forward Looking and Plan Oriented Pragmatist}

Type 1 decision makers may be characterised as forward looking and plan oriented. This group clearly preferred well defined and structured plans over a flexible and adaptable IS resilience plan, as exemplified by this particular highly-ranked statement: "IS resilience plan that is well defined and structured" (rank 7). It is evident that type 1 decision makers were more concerned about anticipating events in advance, as exemplified by these two highly ranked statements: "Ability to anticipate surprises and crises" (rank 2) and "Ability to identify key risks" (rank 4). Another important characteristic of this type is that they are forward looking and pragmatist. This is supported by the group's intention to provide reliable, continuous and consistent service to their customers and also want to assure that the IS resilience plan is well integrated with their business strategy.

\section{Type 2: Mindfully Managing the Unexpected}

This CEO showed some very interesting, pragmatic, unique and mindful characteristics and thus emerged as a separate type. He is a CEO of a small medium enterprise whose core business is to provide software solutions. He has been running this company for 30 years, and has a significant client base both in New Zealand and overseas.

According to him, "Resilient and accessible critical facilities (e.g. back-up systems, redundancy of data)" and "Setting up information disaster recovery system (e.g., disk redundancy, backup facility)" are of utmost importance. He also mentioned that the critical resources to his company are the staff members. "If something happens to 
them then we will lose the intellectual property. [As a consequence] cannot maintain connection with our customers. Staffs are 'key' to us [SMEs]". When probed on this and questioned about whether his company maintains a knowledge repository, he said that, "if you do not have a staff member then you cannot do anything. Maintaining knowledge repository is not going to solve this problem. Another important aspect of his business is to "ensure data security", when probed on this he mentioned that "our business is Data; we have to do everything possible to make sure that it is secured." He mentioned that he is not a process oriented person. His leadership style is empowering and supportive and he has always been like that. In other words, he has not changed his leadership style after the earthquake. In his own words, "...you have to remember that you are dealing with intelligent peoples...they do not required to be micromanaged rather they want a supportive leadership in place. I employ people who are capable of learning and doing jobs. I support them to do their job. While employing staff I make sure that they are smart, bright...I mean quick learner, flexible and adaptable."

As mentioned before this CEO is not a process driven person while probed on this he mentioned that, "planning is important until the disaster struck, while in crisis mode then you have to start thinking the unthinkable." After the series of devastating earthquakes he has done three things which he thinks will make his company more resilient. Firstly, he has put a formal succession plan in place. His company now has a person who he has mentored for years who can look after this business without compromising the business values. Second thing that he has done is, setting up a second location where the whole team can move within two hours and continue business as per usual. Lastly, he has started diversifying his business to more locations, "...l am diversifying my client base. Your business can be resilient and have very little downtime but your client's business can be liquidated, so we are now entering new markets." He further explained that, "Providing the organizational units with information for 24 hours a day, 7 days a week" is absolutely not critical as they have offsite remote back up facilities and they have stored procedures and triggers which will take care of the day to day business of their clients. If they require them to make any alterations then they can do it as long as they can go to their second location and have all the knowledge resources (primarily the staffs) intact.

On one hand, any type of planning is absolutely not a priority for this decision maker and he neither consider "ability to anticipate surprises and crises" nor "Ability to identify key risks" as the top priorities rather he thinks it is far more important to "Practice thinking the unthinkable". $\mathrm{He}$ is strong advocate of resilient and accessible critical facilities (e.g. back-up systems, redundancy of data), setting up information disaster recovery system (e.g., disk redundancy, backup facility) and setting up information and disaster recovery system, which includes reliable back up facilities and redundancy and replication of data. $\mathrm{He}$ showed significant level of mindfulnessbased resilience and decision making under crisis situation. We will discuss about mindfulness-based decision making in detail at the end of this section.

\section{Type 3: Myopic and Process Oriented Pragmatist}

The members in Type 3 are concerned about organization and structure. "Providing the organizational units with information for 24 hours a day, 7 days a week" (rank 1), "Committed, effective and accountable leadership of IS resilience planning and implementation" (rank 2) and "Select suppliers with robust resilience plan" (rank 3) were factored as the top three most important statements. These decision makers place greater value upon resource allocation and internal efficiency of the organisation, they are more focused on 
keeping the operations reliable and efficient, and they also want to see a responsible and reliable leadership structure in place. The comments suggest that the members in this group are interested in efficient business process and data security, as exemplified by "Providing reliable and consistent services to customers" (rank 6) and "Ensuring data security" (rank 7).

It is evident from that Type 1 and Type 3 are routine based approaches, but Type 2 demonstrates mindfulness based reliability. Routine-based approaches are commonly advocated in the Information Systems literature. This approach is designed in advance, usually by top managers (in our case CEOs) and applied by the staffs. Procedures are designed to decrease the need for creative human involvement in the moment of need, so that errors, unwanted variation and wastes can be prevented. Routine-based approaches depend on a match between situation and response. This process may work very well under normal conditions, but is questionable under crisis or uncertain situations. On the other hand, mindfulness-based approaches focus on promoting highly situated human cognition as a solution to organisational problems. According to Weick and Sutcliffe (2007), mindful response to a particular situation is not an attempt to make the best choice from among available options but to create options, which echoed the words of the Type 2 CEO when he mentioned "practice thinking the unthinkable."

Interestingly none of the types found "supplier involvement to plan for IS resilience" to be critical, the reason may be that all our participants are from service industry and supplier involvement may not be very essential for them. If we include respondents from the manufacturing industry then supplier involvement may emerge as an important attribute. According to Zhu and Chen (2014), organisations have a tendency to imitate each other when it comes to strategy, particularly in times of uncertainty. Copying what other companies do gives their decisions legitimacy and saves, or at least reduces the cost of search and experimentation. Contrary to our expectation, however, one thing that appeared consistently from the analysis is that none of these types are interested on competitor analysis in order to prepare for IS resilience. When probed on this they mentioned that "it [planning] is very specific to your organisation and it is best to know your strengths and weaknesses, so [there is] no point copying your competitor's strategy. ...though while planning your own keep an open eye and refer to the best practices within the industry."

\section{Conclusion}

We have identified a gap in research related to information systems resilience in SMEs. Accordingly, we conducted an extensive literature review to identify differences between large-scale enterprises and SMEs with respect to IS resilience and undertook an empirical study using Q-sort instrumentation to analyse key issues. We used Agency Theory to establish the decision priority differences between SMEs and large organisations. This study contributes to the limited body of knowledge on IS resilience in SMEs in four ways. Firstly, we have developed and tested an instrument to capture the decision priorities of SME CEOs. Secondly, we propose a definition of organisational IS resilience. Thirdly, our research shows that Agency Theory is predictive to interpret decision priorities of SME CEOs. Lastly, this is the first attempt to understand the IS resilience decision priorities of SME CEOs in lens of Agency Theory, and it appears to be valid.

The $Q$ methodology does have some weaknesses. It is a small-sample technique, and the sample of items and participants is usually purposive, and the results lack generalizability. However, since the goals of Q-methodology are interpretive, and the concourse is the unit of analysis rather than the people, this is usually not considered a weakness by Q-method practitioners. This study is a starting point for further research 
into the IS resilience in SMEs. Also, the sample was restricted to service SMEs.

There are a number of avenues of future research, including examining a greater range of organisations. Future empirical research should attempt to understand the IS resilience decision priorities and characteristics of resilient organisations.

Finally, results have implications both for researchers who are looking for theories that explain the importance of IS resilience and business managers and owners who are challenged with decisions about how to design resilient information system framework for their organisation.

\section{References}

Battisti, M., Lee, L., and Cameron, A. (2009). Changing Business Focus-People, Planet and Profit : A Report of New Zealand SMEs and their Sustainability Practices. Wellington, New Zealand: New Zealand Centre for Small and Medium Enterprise Reserach Massey University.

Berman, J.A., Gordon, D.D., and Sussman, G., (1997), A study to determine the benefits mall business firms derive from sophisticated planning versus less sophisticated types of planning. The Journal of Business and Economic Studies, 3(3), pp.1-11.

Bhamra, R., Dani, S., and Burnard, K. (2011). Resilience: the concept, a literature review and future directions. International Journal of Production Research, 49(18), pp.5375-5393.

Brown, S. R. (1980). Political subjectivity: applications of $Q$ Methodology in Political Science. New Haven, CT: Yale University Press.
Comfort, L. K. (2001). Complex systems in crisis: anticipation and resilience in dynamic environments. Journal of Contingencies and Crisis Management, pp.144-158.

Cragg, P. B., and King, M. (1993). Smallfirm Computing : Motivators and Inhibitors. MIS Quarterly, pp.47-60.

Dennis, K. (1988). Q-methodology: New perspectives on estimating reliability and validity. In O.L. Strickland \& C.F. Waltz (Eds.), Measurement of nursing outcomes. Vol. 2. Measuring nursing performance: Practice, education, and research (pp. 409-419). New York: Springer.

Eisenhardt, K. M. (1989). Agency Theory: an assessment and review. Academy of Management Review, 14(1), pp.5774.

Fama, E. F., and Jensen, M. C. (1983). Separation of Ownership and Control. Journal of Law and Economics, 26(2), pp.301-325.

Ghobadian, A., and O'Regan, N. (2006). The Impact of Ownership on Small Firm Behaviour and Performance. International Small Business Journal, 24(6), pp.555-586.

Gibb, F., and Buchanan, S. (2006). A Framework for business continuity management. International Journal of Information Management, 26(2), pp. 128-141.

Gibson, C and Tarrant, M. E (2010) A Conceptual Models Approach to Organisational Resilience, Australian Journal of Emergency Management, 25(2), pp.6-12.

Goodwin, B. (2005, August 30). Business Continuity Spotlight falls on SMEs. Computer Weekly, pp. 10. 
Gurbaxani, V., and Whang, S. (1991). The impact of information systems on organizations and markets. Communications of the ACM, 34(1), pp.59-73.

Hatton, T., Seville, E., and Vargo, J. (2012). Improving the resilience of SMEs : policy and practice in New Zealand. Christchurch, New Zealand: Asia Pacific Economic Co-operation (APEC).

IBM. (2011). Key trends driving global business resilience and risk. IBM Global Technology Services.

Jensen, M. C., and Meckling, W. H. (1976, October). Theory of the firm : managerial behaviour, agency costs and ownership structure. Journal of Financial Economics, 3(4), pp.305-360.

Klaus, T., Wingreen, S. C., and Blanton, J. E. (2010). Resistant groups in enterprise system implementations: a Q-methodology examination. Journal of Information Technology, 25(1), pp. $91-106$.

Lee, C. K. and Wingreen, S. C. (2010). Transferability of knowledge, skills, and abilities along IT career paths: an Agency Theory perspective. Journal of Organizational Computing and Electronic Commerce, 20, pp. 23 - 44.

Massey, C. (2005). Entrepreneurship and small business management in New Zealand. Auckland: Pearson Education.

McManus, S. (2008). Organisational Resilience in New Zealand. Doctor of Philosophy, University of Canterbury, Christchurch.

Ministry of Economic Development. (2012). SMEs in New Zealand: Structure and Dynamics. Wellington, New Zealand: Ministry of Economic Development.
Muller, G., Koslowski, T., and Accorsi, R. (2013). Resilience - A New Research Filed in Business Information Systems. ACM Symposium on Business Computing, pp.1-12.

OECD. (2010). SMEs, Entrepreneurship and Innovation. Paris: Organisation for Economic Co-operation and Development.

Paton, D. (2007). Measuring and Monitoring Resilience in Auckland. GNS Science, pp. 33-39.

Saunders, M. (1997). Strategic Purchasing and Supply Chain Management. London, Pitman.

Sayana, S. A. (2005). Auditing Business Continuity. Information Systems Control Journal, pp.37-39.

SBA Office of Advocacy (2012). Frequently asked questions. Electronic copy available at https://www.sba.gov/sites/ default/files/FAQ_Sept_2012.pdf.

Seville, E. (2009) Resilience: Great concept but what does it mean for organisations? Tephra, 22, pp.9-15.

Singleton, T. W. (2011). What Every IT Auditor Should Know About Backup and Recovery. ISACA Journal, 1-2.

Statistics New Zealand. (2010). Business Operations Survey 2010. Wellington: Statistics New Zealand.

Stephenson, W. (1986a). Protoconcursus: The concourse theory of communication: I. Operant Subjectivity, 9(2), Jan 1986. pp. 37-58.

Stephenson, W. (1986b). Protoconcursus: The concourse theory of communication: II. Operant Subjectivity, 9(3), Apr 1986. pp. 73-96.

Stephenson, W. (1986-1988). William James, Niels Bohr, and complementarity. The Psychological Record, vols 36-38. 
Storey, D., and Greene, F. (2010). Small Business and Entrepreneurship. Harlow, UK: Pearsons Education.

Teoh, S. Y., and Zadeh, H. S. (2013). Strategic Resilience Management Model:Complex Enterprise Systems Upgrade Implementation. Pasific Asia Conference on Information Systems, pp. 88-95. Jeju Island, Korea: PACIS.

Thong, J. Y. (1999). An Integrated Model of Information Systems Adoptation in Small Businesses. Journal of Management Information Systems, 15(4), pp.187-214.

Vargo, J., and Seville, E. (2011). Crisis strategic planning for SMEs: finding the silver lining. International Journal of Production Research, 49(18), pp. 5619-5635.

Vargo, J., and Stephenson, A. V. (2010). Measuring Organizational Resilience. World Conference on Disaster Management (pp. 44-51). Toronto, Canada: World Conference on Disaster Management.
Watts, S and Stenner, P. (2012). Doing $Q$ methodological research: theory, method and interpretation. London: Sage Publications.

Weick, K. E., and Sutcliffe, K. M. (2007). Mindfulness and the quality of organizational attention. Organization Science, pp.514-531.

Wingreen, S. C. and Blanton, J. E. (2017). IT professionals' person-organization fit with IT training and development priorities. Information Systems Journal, 27, 20 January 2017.

Wingreen, S. C., LeRouge, C. and Blanton, J. E. (2009). Structuring Training for IT Professionals and the Firm: An application of the Q-methodology, International Journal of Global Management Studies, 1(1), pp.53-67.

Zhu, D. H., and Chen, G. (2014). CEO Narcissism and the Impact of Interlocks on Corporate Strategy. Electronic copy available at: http://ssrn.com/abstract=2429586. 


\section{Appendix A}

\section{Q-SAMPLE}

Let us imagine a scenario, such as:

"Your business has been interrupted by a major incident. You have no access to your premises, IT systems and business records. Some of your employees are injured or dead. You do not know how long the outage is going to last. If you are trying to plan ahead, anticipating this scenario, what would your priorities be?"

Q-sort distribution:

Keeping in mind the above scenario, rate which statements are important according to your experience during Information Systems Resilience planning. Assign the statements "from the outside in", that is, decide on two "very important" and "very unimportant" statements first, then select four statements each for the "important" and "unimportant" categories, and six statements each for "somewhat important" and "somewhat unimportant". The last thirteen statements need not be sorted, and will be categorized as "neutral". Enter the number to the left of each statement in the spaces provided. Please ensure that you enter a statement only once for each set of priorities.

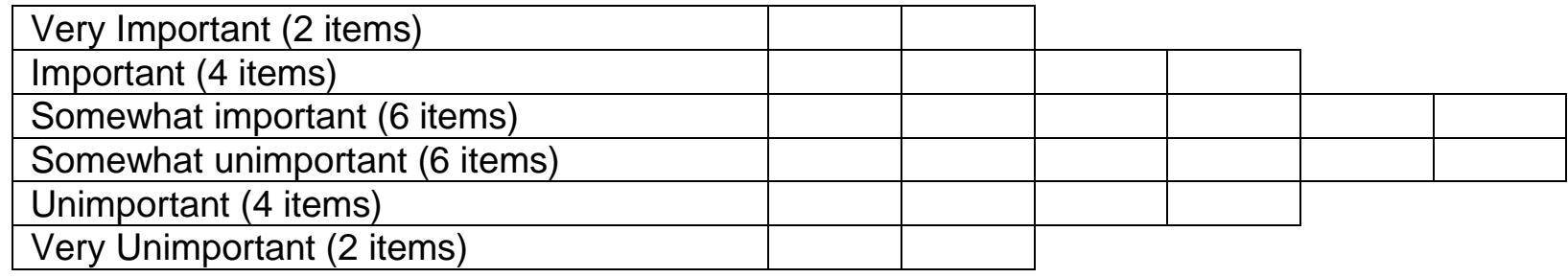

\section{Q-Statements}

1. IS Disaster Recovery plans informed by understanding of underlying causes of vulnerability and other factors outside organisation's control.

2. Organisation IS Continuity plans, developed through participatory processes, put into operation and updated periodically.

3. Organisation's IS resilience plan shared with all suppliers.

4. Organisation hazard/risk assessments carried out which provide comprehensive picture of all major hazards and risks faced by organisation (and potential risks).

5. On-going monitoring of hazards and risks and updating of plans.

6. Organisational vulnerability and capacity assessments carried out which provide comprehensive picture of vulnerabilities and capacities.

7. Resilient and accessible critical facilities (e.g. back-up systems, redundancy of data).

8. Top management support and commitment to IS resilience.

9. IS resilience can provide an organisation with an edge over its competitors.

10. Our competitors are developing and enhancing their IS resilience capabilities.

11. A sound IS resilience plan will help us to win more business contracts.

12. A sound IS resilience plan will help us to pay lesser insurance premium.

13. A sound IS resilience plan will help our organisation to make more efficient use of resources. 
14. Long-term IS Resilience, Business Continuity, Disaster recovery justification and planning.

15. Competitor analysis.

16. Setting up information disaster recovery system (e.g., disk redundancy, backup facility).

17. Study resilience strategies of competitors.

18. Select suppliers with robust resilience plan.

19. Use IS network to communicate with the customers.

20. Use IS networks to connect to supplier's databases.

21. Use cloud computing to back up organisational data.

22. The level of customer involvement in preparing resilience, business continuity and disaster management plans.

23. The extent of follow-up with customers for feedbacks.

24. The level of supplier involvement in preparing resilience, business continuity and disaster management plans.

25 . Ensuring data security

26. Providing reliable and consistent services to Suppliers

27. Providing reliable and consistent services to customers

28. Capability for disaster recovery

29. Providing the organizational units with information for 24 hours a day, 7 days a week

30. Understanding the strategic priorities of top management

31. Aligning IS strategies with the strategic plan of the organization

32. Adapting technology to strategic change
33. IS resilience plan that is well defined and structured

34. IS resilience plan that is flexible and adaptable

35. Ability to identify key risks

36. Ability to anticipate surprises and crises

37. Committed, effective and accountable leadership of IS resilience planning and implementation.

\section{About the Authors}

Amitrajit Sarkar is a Senior Lecturer of Software Engineering and Information Systems at Ara Institute of Canterbury, in Christchurch, New Zealand. $\mathrm{He}$ has published widely in Software engineering and Management Information Systems. His main research interests include IT Governance and IS resilience, which is an aspect of organisational resilience. IT Governance is focused on the leadership, structures and processes that ensure that an organisation's information technology sustains and extends the overall organisation's strategies and objectives. Amitrajit is currently exploring decision priorities of top management in context to Information Systems resilience. His current research agenda include comparative studies between India and New Zealand in order to understand the decision priorities of key decision makers from both countries in context to Information Systems resilience and establish a framework for modelling Information Systems resilience and decision making.

Stephen C. Wingreen is Senior Lecturer of Information Systems and Decision Sciences at the University of Canterbury, in Christchurch, New Zealand. Dr. Wingreen pursues scholarly interests in the fields of information technology professionals, information systems resilience, technology and culture, applications of Q-methodology 
and Concourse Theory in the decision sciences, and occasional topics on electronic commerce trust. $\mathrm{He}$ has published his research in the Journal of Business Ethics, Information Systems Journal, Journal of Information Technology, and Human Resource Management, to name a few.

Professor Paul Cragg is an ex professor of Information Systems at the University of Canterbury, in Christchurch, New Zealand.
His research interests include any aspect associated with the use, management \& impact of IT in SMEs. For example: IS best practices, IS benchmarking, factors influencing the adoption \& impact of the internet, the alignment of IT \& business strategy, measuring IT sophistication, IS Security, IT impact on firm performance, IT competences. He has published his research in many leading journals in Information Systems and Management. 